\title{
Antioxidant, Antibacterial activity and Brine shrimp toxicity test of some Mountainous Lichens from Nepal
}

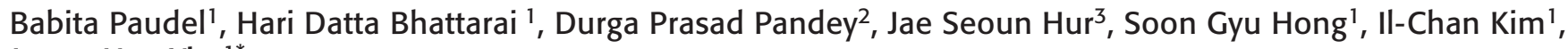 \\ Joung Han Yim ${ }^{1 *}$ \\ ' Division of LifeSciences, Korea Polar Research Institute, KOPRI, Songdo Technopark, Songdo-dong 7-50, Yeonsu-gu, Incheon 406-840, South Korea, Tel. +82-32-260- \\ 6340, Fax +82-32-260-6301 \\ 2 Research Center for Applied Science and Biotechnology, Tribhuvan University, Kirtipur, P.O.Box. 5026. Kathmandu, Nepal. Tel. 977-1-4330348 \\ ${ }^{3}$ Korean Lichen Research Institute, Sunchon National University, Suncheon 540-742, Korea
}

\begin{abstract}
A total of twenty four lichen species belonging to six families were collected from mountainous region of Nepal. The methanol extracts of each species were tested for antimicrobial and antioxidant activities in vitro. It was found that extracts of twenty one lichen species were active against B. subtilis and seven species were active against S. aureus. Similarly, in DPPH assay, three species Peltigera sp., Cladonia sp., and Canoparmelia sp. showed comparable activity with commercial standard, BHA. In $\mathrm{ABTS}^{+}$assay, extracts of Parmoterma sp., Ramalina sp., Peltigera sp. and Cladonia sp. showed stronger activity than ascorbic acid. The observed data after comparison with previously published reports indicated that the high altitude lichens contain stronger antioxidant and antibacterial constituents. Similarly, the methanol extracts of Heterodermia sp. and Ramalina sp. showed comparable toxicity effect with commercial standard berberine chloride indicating a potent source of anticancer drugs.
\end{abstract}

Key words: Antibacterial; Antioxidant; Nepal lichens; Free radicals

\section{INTRODUCTION}

Lichens are cosmopolitan in distribution from arctic to tropical regions and from plains to the highest mountains and some survive in the extreme environment of deserts. From the ancient time, lichens have been used for various purposes such as food, dyes, perfumes, remedies in folk medicines and decoration. Various lichens metabolites from several classes as- aliphatic acids, pulvinic acid derivatives, depsides and depsidones, dibenzofurans, diterpenes, anthraquinones, naphthoquinones, xanthones as well as epidithiopiperazinediones have been described. These compounds have shown a wide ranges of biological activities such as antibiotic, antimycobacterial, antiviral, antiinflammatory, analgesic, antipyretic, antiproliferative, cytotoxic effects and antioxidant properties ${ }^{1-2}$.

To overcome the pace of drug resistance phenomenon in several pathogenic bacteria, several novel antibacterial compounds need to be developed. After the discovery of penicillin a number of lichens were screened for antibacterial activity $^{3}$ between 1940 and 1950. Several lichen compounds were found active against gram-positive bacteria and mycobacteria ${ }^{4}$.

Reactive oxygen species (ROS) are harmful or lethal for living organism ${ }^{5}$. ROS are ions or very small molecules which include free radicals, oxygen ions and peroxides. ROS are formed inside the living organisms as natural byproducts of the normal metabolism of oxygen and help in cell signaling. Thus, living organisms accumulate various ROS through both normal metabolic processes and exogenous sources like environmental stresses such as UV light, cigarette smoke, environmental pollutants, $\gamma$-radiation. Various types of ROS are produced inside the living organisms ${ }^{6}$ such as hypochlorous acid $(\mathrm{HClO})$, hydrogen peroxide $\left(\mathrm{H}_{2} \mathrm{O}_{2}\right)$ and free radicals such as the hydroxyl radical $(\cdot \mathrm{OH})$, superoxide anion $\left(\mathrm{O}_{2}{ }^{-*}\right)$, alkoxy and peroxy radicals ( $\mathrm{RO}^{*}$ and $\left.\mathrm{ROO}^{*}\right)$, peroxynitrite $\left(\mathrm{ONOO}^{-}\right)$. These ROS are highly reactive and unstable due to the presence of unpaired electron in their outer shell. They have been associated with several diseases such as inflammation, cardio vascular diseases, cancer, aging-related disorders, metabolic disorders, and atherosclerosis ${ }^{7}$. ROS react with various cellular components including DNA, proteins, lipids, fatty acids. Thus, the reaction between ROS and cellular components lead to damage DNA, attack unsaturated fatty acids and cause membrane lipid peroxidation, decreases in membrane fluidity, loss of enzyme receptor activities, and damage to membrane proteins, ultimately leading to cell inactivation ${ }^{8}$. Most of the known antioxidant activities of lichens and their chemical investigations are derived from the species of tropical and sub-tropical origin. Fewer studies have been conducted on the antioxidant activities of lichens from the extreme environment such as the Antarctic regions ${ }^{9-10}$

Nepal is a mountainous country which contains a diverse geographic locations ranging from $60 \mathrm{~m}$ to $8848 \mathrm{~m}$ above sea level. In Nepal, 465 species of lichens $(2.3 \%$ of the world species) from 79 genera (19.7\% of the world genera) have been recorded, of which 48 species are endemic ${ }^{11}$. Because of its unique bio-geographic location, altitudinal variation and diverse climatic and topographic conditions, several lichen species can be obtained with in a small geographical area. Traditionally, a variety of lichens species are used in medication for several diseases such as inflammation, dysentery, vomiting by various indigenous community people. There are very few reports of chemical investigation of lichens 
species from $\mathrm{Nepal}^{2}$. In this report, we describe the biological activity of some mountainous lichen species which are yet to be phytochemically explored.

\section{MATERIAL AND METHODS}

Collection and identification of lichen species

Twenty-four species (Table 1) were collected from three different geographical locations of Nepal in late September and in early October, 2010. Six lichen species: NL-1 to NL-6 were collected from Nargarjun mountain, Nepal (E85 $21^{\prime}$ $\left.85^{\circ} 22^{\prime}, N^{\prime} 27^{\circ} 19^{\prime}-27^{\circ} 23^{\prime}\right)$. Similarly, nine lichen species: NL-7 to NL-15 were collected from Sarankot $\left(E 83^{\circ} 57^{\prime}-83^{\circ} 58^{\prime}\right.$, N28 $8^{\circ} 14^{\prime}-$ $\left.28^{\circ} 15^{\prime}\right)$, Pokhara, Nepal and remaining nine lichen species: NL-16 to NL-24 were collected from Srinagar, Palpa, Nepal $\left(\mathrm{E} 85^{\circ} 17^{\prime}-85^{\circ} 34^{\prime} ; \mathrm{N} 27^{\circ} 34^{\prime}-27^{\circ} 44^{\prime}\right)$. All the lichen specimens were identified by phylogenetic analysis of ITS rDNA sequences with sequences available from GeneBank sequence database. The voucher specimens were kept in lichen herbarium, Korea Polar Research Institute, KOPRI, Incheon, South Korea.

TABLE 1

List of test lichen species and their methanol extracts' antibacterial, antioxidant and toxicity activities

\begin{tabular}{|c|c|c|c|c|c|c|c|c|c|c|}
\hline \multirow[t]{2}{*}{ Symbol } & \multirow[t]{2}{*}{ Lichen species } & \multirow[t]{2}{*}{ Family } & \multicolumn{2}{|c|}{$\begin{array}{l}\text { Inhibition zone } \\
\qquad(\mathrm{mm})\end{array}$} & \multicolumn{2}{|c|}{ MIC $(\mu \mathrm{g} / \mathrm{mL})$} & \multicolumn{2}{|c|}{$\begin{array}{l}50 \% \text { inhibition conc. } \\
\quad\left(\mathrm{IC}_{50}\right)(\mu \mathrm{g} / \mathrm{mL})\end{array}$} & \multirow[b]{2}{*}{$\begin{array}{l}\text { Reducing } \\
\text { power }^{\mathrm{a}}\end{array}$} & \multirow{2}{*}{$\begin{array}{c}\begin{array}{c}\mathrm{LC}_{50} \text { conc. } \\
(\mu \mathrm{g} / \mathrm{mL})\end{array} \\
\text { Artimia sp. }\end{array}$} \\
\hline & & & $\begin{array}{c}\text { B. } \\
\text { subtilis }\end{array}$ & $\begin{array}{c}\text { S. } \\
\text { aurens }\end{array}$ & $\begin{array}{c}\text { B. } \\
\text { subtilis }\end{array}$ & S. aurens & DPPH & ABTS & & \\
\hline NL-1 & Parmoterma sp. & Parmeliaceae & 9 & na & $85 \pm 8.5$ & na & $40.5 \pm 4.1$ & $35.5 \pm 7.1$ & $2.6 \pm 0.1$ & 400 \\
\hline NL-2 & Cladonia sp. & Cladoniaceae & 17 & 9 & $11.7 \pm 0.6$ & $83 \pm 6.7$ & $38.5 \pm 3.8$ & $51.6 \pm 6.5$ & $1.7 \pm 0.1$ & 200 \\
\hline NL-3 & Parmoterma sp. & Parmeliaceae & 10 & na & $81.2 \pm 7.5$ & na & $34.4 \pm 4.4$ & $45.6 \pm 6.7$ & $4.6 \pm 0.4$ & nt \\
\hline NL-4 & Heterodermia sp. & Physciaceae & 11 & na & $65.2 \pm 5.2$ & na & $41.6 \pm 2.5$ & $60.3 \pm 5.1$ & $3.4 \pm 0.3$ & 100 \\
\hline NL-5 & Heterodermia sp. & Physciaceae & 10 & na & $77.7 \pm 5.1$ & na & $51.8 \pm 7$ & $84.2 \pm 6.8$ & $2.9 \pm 0.4$ & nt \\
\hline NL-6 & Usnea sp. & Parmeliaceae & 25 & 18 & $35.9 \pm 2.4$ & $89.2 \pm 8.2$ & $45.2 \pm 5.2$ & $86.6 \pm 10.1$ & $4.5 \pm 0.3$ & nt \\
\hline NL-7 & Parmotrema sp. & Parmeliaceae & 20 & na & $21.7 \pm 1.3$ & na & $45.7 \pm 0.9$ & $50.3 \pm 5.9$ & $3.4 \pm 0.6$ & 200 \\
\hline NL-8 & Coccocarpia sp. & Coccocarpiaceae & 14 & na & $79.4 \pm 6.4$ & na & $72.1 \pm 5.4$ & $48.2 \pm 3.9$ & $2.8 \pm 0.4$ & $\mathrm{nt}$ \\
\hline NL-9 & Heterodermia sp. & Physciaceae & 11 & na & $76.1 \pm 8.5$ & na & $49.9 \pm 3.8$ & $65.2 \pm 10.5$ & $3.8 \pm 0.2$ & 200 \\
\hline NL-10 & Parmotrema sp. & Parmeliaceae & 11 & 10 & $11.1 \pm 0.2$ & $18.2 \pm 0.8$ & $61.8 \pm 7.4$ & $42.3 \pm 3.4$ & $3.5 \pm 0.6$ & 200 \\
\hline NL-11 & Parmotrema sp. & Parmeliaceae & 16 & 11 & $23.2 \pm 2.6$ & $35.6 \pm 2.7$ & $98.6 \pm 10.7$ & $60.3 \pm 14.4$ & $6.2 \pm 0.8$ & nt \\
\hline NL-12 & Peltigera sp. & Peltigeraceae & na & na & na & na & $5.6 \pm 0.2$ & $6.9 \pm 0.3$ & $1.3 \pm 0.1$ & nt \\
\hline NL-13 & Heterodermia sp. & Physciaceae & na & na & na & na & $48.8 \pm 5.7$ & $95.7 \pm 9.3$ & $6.7 \pm 1.3$ & 200 \\
\hline NL-14 & Bulbothrix sp. & Parmeliaceae & 19 & na & $41.1 \pm 4.2$ & na & $41.1 \pm 3.8$ & $71.8 \pm 5.6$ & $4.9 \pm 1.7$ & 400 \\
\hline NL-15 & Heterodermia sp. & Physciaceae & 9 & na & $89.8 \pm 8.2$ & na & $43.4 \pm 4.1$ & $99.9 \pm 8.7$ & $3.7 \pm 0.6$ & 100 \\
\hline NL-16 & Cladonia sp. & Cladoniaceae & na & na & na & na & $10.1 \pm 2.2$ & $7.0 \pm 0.3$ & $1.8 \pm 0.2$ & 200 \\
\hline NL-17 & Ramalina sp. & Ramalinaceae & 26 & na & $15.1 \pm 1.2$ & na & $32.9 \pm 3.5$ & $52.0 \pm 5.5$ & $2 \pm 0.1$ & $\mathrm{nt}$ \\
\hline NL-18 & Ramalina sp. & Ramalinaceae & 24 & 11 & $8.5 \pm 0.1$ & $65.3 \pm 5.7$ & $8.7 \pm 2.7$ & $33.2 \pm 2.8$ & $1.2 \pm 0.1$ & 100 \\
\hline NL-19 & Canoparmelia sp. & Parmeliaceae & 17 & 10 & $4.2 \pm 0.02$ & $32.6 \pm 2.4$ & $80.7 \pm 8.4$ & $68 \pm 7$ & $3.7 \pm 0.5$ & nt \\
\hline NL-20 & Parmotrema sp. & Parmeliaceae & 31 & 16 & $2.1 \pm 0.03$ & $21.4 \pm 2.2$ & $45.7 \pm 6$ & $32.4 \pm 3.1$ & $2.3 \pm 0.1$ & nt \\
\hline NL-21 & Everniastium sp. & Parmeliaceae & 11 & 11 & $91.9 \pm 11$ & $71.7 \pm 5.9$ & $70.1 \pm 8.5$ & $70.5 \pm 6.9$ & $4.1 \pm 0.1$ & $\mathrm{nt}$ \\
\hline NL-22 & Parmotrema sp. & Parmeliaceae & 9 & na & $85.3 \pm 8.2$ & na & $58.4 \pm 10.1$ & $42.8 \pm 6.1$ & $2.4 \pm 0$ & na \\
\hline NL-23 & Parmotrema sp. & Parmeliaceae & 14 & na & $99.9 \pm 10$ & na & $61.2 \pm 5.9$ & $31.4 \pm 5.3$ & $2.6 \pm 0.2$ & nt \\
\hline NL-24 & Parmotrema sp. & Parmeliaceae & 12 & na & $87.6 \pm 4.7$ & na & $41.7 \pm 5.9$ & $73.7 \pm 6.2$ & $2.7 \pm 0.1$ & na \\
\hline BHA & - & - & - & - & - & - & $3.5 \pm 0.2$ & - & - & \\
\hline Trolox & - & - & - & - & - & - & - & $46.4 \pm 0.1$ & - & \\
\hline Ampicillin & - & - & - & - & $0.4 \pm 0.1$ & $0.35 \pm 0.01$ & - & - & - & \\
\hline $\begin{array}{l}\text { Berberine } \\
\text { chloride }\end{array}$ & & & & & & & & & & 8.4 \\
\hline
\end{tabular}

a $1 \mu \mathrm{g}$ of BHT equivalent; na-no activity; nt, not tested 


\section{Extraction}

A completely freeze-dried and grinded lichen samples (Table $1)$ were extracted separately in a mixture of methanol and water $(80: 20 \mathrm{v} / \mathrm{v})$. Then, the extract was filtered and solvent was evaporated at $45^{\circ} \mathrm{C}$ in vacuum. This extraction procedure was repeated three times to ensure the complete extraction of extractable compounds. Extracts were washed with hexanes three times to remove pigments and fats. The extracts were then lyophilized and stored at $-20^{\circ} \mathrm{C}$ until further use.

\section{Chemical reagents}

Antioxidant assay kit (Product code CS0790), chemicals and reagents used for in vitro antioxidant assyas were purchased from Sigma-Aldrich, USA. All used chemicals and reagents were of analytical grade. The solvents used during extraction were HPLC grade and were purchased from DUKSAN pure chemicals Co. Limited, Korea. The media, NA (Nutrient agar), NB (Nutrient broth) and YM (Yeast mannitol), used for antimicrobial assays were purchased from Difco USA.

\section{Antimicrobial Assay}

\section{Target microorganisms and culture condition}

Five clinical microorganisms, including two Gram-positive (Bacillus subtilis KCTC1022 and Staphylococcus aureus KCTC3881) and two Gram-negative (Escherichia coli KCTC1039 and Pseudomonas aeruginosa KCTC1636) bacteria and a fungus, Candida albicans KCTC 7965, were purchased from Korean Collection of Type Culture (KCTC). Bacterial strains were grown on nutrient agar (NA) at $30-37^{\circ} \mathrm{C}$ and $\mathrm{C}$. albicans was grown on yeast mannitol (YM) agar at $25^{\circ} \mathrm{C}$.

\section{Disk diffusion assay}

Antimicrobial testing was carried out by using a previously described paper disk assay ${ }^{12}$. Sterile paper disks (Adventic, Japan) of $8 \mathrm{~mm}$ size were loaded with lichen extract at a concentration of $500 \mu \mathrm{g} /$ disk in triplicate and allowed to dry at room temperature under sterile conditions. The disks were kept on the surface of NA (Nutrient agar) or YM (Yeast mannitol) agar plates, which had been freshly swabbed with the overnight grown broth culture of the target microbial strains. Then, the plates were incubated at optimum growth temperature of each strain for $24-48 \mathrm{~h}$. The zones of inhibition around the lichen extract loaded paper disks were reflective of the antimicrobial effectiveness of the extract. Paper disks loaded with methanol, a solvent used to dissolve crude extract, were used as negative controls and the paper disks loaded with ampicillin were used as positive controls.

\section{Determination of minimum inhibitory concentration (MIC)}

MIC was determined by a broth dilution method ${ }^{13}$. Serial dilutions of lichen extract ranging from 0 to $1000 \mu \mathrm{g} / \mathrm{mL}$ in $5 \mathrm{~mL}$ of nutrient broth in triplicate were prepared in $15 \mathrm{~mL}$ sterile falcon tubes. The range of the test concentration for the extracts was determined after completion of an initial range finding experiment. An overnight grown broth culture of the target strains seed, having a final cell density $10^{5} \mathrm{CFU} / \mathrm{mL}$, was used to inoculate in fresh nutrient broth media containing a range of test extract concentrations. The inoculated tubes were incubated at optimum temperature of each target strain (Table 1) and shaken at $250 \mathrm{rpm}$ for $24 \mathrm{~h}$. Microbe growth was measured spectrophotometrically (SCINCO-AMERICA) by absorbance at $600 \mathrm{~nm}$. The MICs were analyzed after the linear regression analysis of the experimental data. Ampicillin was used as a positive control.

Antioxidant assay

Various in vitro antioxidant activities such as DPPH and $\mathrm{ABTS}^{*+}$ free radical scavenging capacity ${ }^{14-15}$ and $\mathrm{Fe}^{3+}$ reducing power ${ }^{16}$ of the lichen extracts were determined by comparing with available commercial standards (Table 1 ). These experiments were modified at various degrees as described previously ${ }^{17}$. The experiments were conducted in triplicate and data were analyzed by using linear regression analysis.

\section{Brine shrimp lethality test}

Brine shrimp lethality test (BST) was used to evaluate the toxicity of various lichen's crude extracts ${ }^{18}$ with slight modification. The eggs of $A$. salina were hatched in aerated seawater in light at $25{ }^{\circ} \mathrm{C}$. The hatched active larvae will be attracted towards the direction of light. The active larvae (about 100) are selected and treated with various concentrations of test samples $(0-2000 \mu \mathrm{g} / \mathrm{ml})$. The effects of test samples were monitored after $24 \mathrm{~h}$ of treatment by observing the live larvae. The mortality rate of the larvae indicated the toxicity of the test samples. Berberine chloride a standard anticancer drug was taken as positive control and brine shrimp larvae in only sea water were taken as negative control.

\section{RESULT AND DISCUSSION}

\section{Antibacterial activity}

In the present study the antimicrobial activities of lichens extracts were determined qualitatively and quantitatively by measuring inhibition zone and MIC values. The experimental data of antimicrobial activities of twenty four lichen species are presented in Table 1. In the first step, antibacterial strength against the Gram-positive bacteria, B. subtilus and S. aurens, Gram-negative bacteria, Escherichia coli and Pseudomonas aeruginosa and the yeast, Candida albicans was measured in terms of zone of inhibition produced by extracts of various lichen species. Eight lichen species NL-2, NL-6, NL-10, NL11, NL-18, NL-19, NL-20 and NL-21_showed the antibacterial activity against $B$. subtilus and $S$. aurens. The anitbacterial activity, as indicated by zone of inhibition size were various among the above eight lichens extract. However, B. subtilus was more suspectible than $S$. aurens to lichens extract.The zone of inhibition for active species extracts $(500 \mu \mathrm{g} /$ disk) was in the range of $9-31 \mathrm{~mm}$ against $B$. subtilus and $9-18 \mathrm{~mm}$ against S. aurens. NL-20 produced highest inhibition zone against $B$. subtilus but NL-6 showed the highest inhibition zone against $S$. aurens. Similarly, seven lichen species NL-5, NL-7, NL-8, NL14, NL-17, NL-23 and NL-24 prdouced remarkable inhibition zone against $B$. subtilus only. In addition, five lichens species NL-1, NL-3, NL-9, NL-15 and NL-22 showed very weak antibacterial activity against $B$. subtilus. Four lichen NL-4, NL- 
12, NL-13, NL-16 did not show inhibition zone upto $500 \mu \mathrm{g} /$ disk. The obtained result showed that none of the lichen extract was active against the Gram-negative bacteria, Escherichia coli and Pseudomonas aeruginosa and the pathogenic fungus, Candida albicans.

The MIC (100\% of growth inhibition) showing by test lichen extracts against two gram positive strains B. subtilus and S. aurens are various (Table 1). Among the tested lichen's extract, NL-18, NL-19 and NL-20 showed comparatively strong antibacterial activity against B. subtilus. Among them, NL20 showed strongest activity against $B$. subtilis while NL-10 showed similar result with S. aurens.

\section{Antioxidant activity}

In this experiment, three in-vitro antioxidant assays based on on electron transfer (ET) or hydrogen atom transfer (HAT) system- (DPPH free radical, ABTS + scavenging capacities and $\mathrm{Fe}^{+3}$ reducing power) were used to investigate the antioxidant activities of methanol-water (80:20) extract of twenty-four lichen species. ET-based assays measured the capacity of an antioxidants which reduce an oxidant by changing the color ${ }^{19}$ Thus, the degree of color change was correlated with antioxidant potential. Antioxidant capacities of methanol extract of all twenty four lichen species are presented in table 1.

$\mathrm{DPPH}$ is commercially available stable free radical in aqueous or methanol solution and becomes a stable molecule by accepting an electron or hydrogen radical from antioxdaint compounds ${ }^{14}$. All the tested lichen extracts and the commercial standard (BHA) exhibited DPPH free radical scavenging capacity in the concentration dependent manner that could easily be read by a spectrophotometer by obtaining a decreased absorbance at $517 \mathrm{~nm}$. BHA is a strong commercial antioxidant agent and the $\mathrm{IC}_{50}$ (50\% inhibition) of this compound was 4.98 $\mu \mathrm{g} / \mathrm{mL}$ in the present experiment. In the present experiment, the test lichens showed the various strengths to scavenge $\mathrm{DPPH}$ free radical. Overall, the $\mathrm{IC}_{50}$ of $\mathrm{DPPH}$ free radical scavenging capacity of twenty-four lichens extract was found between $5.6 \pm 0.2$ and $98.6 \pm 10.7 \mu \mathrm{g} / \mathrm{mL}$. Three species NL-12, NL-16 and NL-18 showed comparatively strong DPPH free radical scavenging capacity. Similarly, NL-1, NL-2, NL-3 and NL-17 showed moderate activity.

$\mathrm{ABTS}^{+}$' scavenging capacities of lichens extracts are presented in table (1). In this reaction system, the chromogen cations of ABTS (2, 2'-azino-bis (3-ethylbenzthiazoline-6sulfonic acid) are produced by oxidizing ABTS with ferryl myoglobin radicals. The ferryl myoglobin radicals are produced by the reaction of metmyoglobin with hydrogen peroxide. The $\mathrm{ABTS}^{+}$free radical produces a green color and can be read spectrophotometrically at $405 \mathrm{~nm}^{15}$. Like trolox, a commercially available vitamin E analogue, the water soluble crude extracts reduced the production of $\mathrm{ABTS}^{+}$radicals in the reaction mixture in a concentration-dependent manner. The rate of scavening capacities were various among different lichen species. Among the twenty-four lichens species tested, nine lichens NL-1, NL-3, NL-10, NL-12, NL-16, NL-18, NL20, NL-22 and NL-23 showed stronger $\mathrm{ABTS}^{+}$' scavenging capacity than commercial standard trolox. Similarly, the other four species NL-2, NL-7, NL-8 and NL-17 showed comparable activity with commercial standard.

It was observed that the reducing power of compound was directly correlated with its potential antioxidant activity ${ }^{20-21}$.
The reducing activities of compounds are based on the presence of reductones, which exert antioxidant effects by donating a hydrogen atom to break the free radical chain ${ }^{22}$. The ferric ion reducing antioxidant (or reducing power) assay measured the electron transferring capacity of the test samples to convert $\mathrm{Fe}^{+3}$ to $\mathrm{Fe}^{+2}$ inside a complex molecule. In the present experiment, the reducing power of the crude extracts of several tested lichen species was comparable with that of the commercial antioxidant, BHT (Table 1).

Toxicity against Artemia salina

A total of hundred percent of Artemia larvae were alive after 24 $\mathrm{h}$ of experiment in the negative control. $\mathrm{LC}_{50}$ of positive control sample was obtained as $8.4 \mu \mathrm{g} / \mathrm{ml}$. The test extract showed $\mathrm{LC}_{50}$ in the range of $100-400 \mu \mathrm{g} / \mathrm{ml}$ even at crude level. The activity of purified compounds can be expected much stronger than that of the berberine chloride. Among the tested lichen extracts, NL-4, NL-15 and NL-18 showed comparatively strong activity.

\section{CONCLUSION}

In conclusion lichens from mountains of Nepal showed comparable antibacterial and antioxidant activities even at crude extract level with commercial standards. In previous studies $^{23}$ antioxidant activity (in term of $\mathrm{IC}_{50}$ ) of lichens extracts from tropical and other mountainous regions were reported in $\mathrm{mg} / \mathrm{ml}$ concentration level. But, in this study we found the activity were in $\mu \mathrm{g} / \mathrm{ml}$ level which means at least thousands times stronger activity. In addition, no or very few bioactive natural products researches of mountainous lichens of Nepalese origin were published so far. Therefore, there is a high probability of getting novel and active antioxidant and antibacterial natural products from these lichens species. Such metabolites could be better candidates for future therapeutic applications. In addition, the A. salina test revealed that lichen extracts even contains anticancer compounds probably stronger than the positive control when tested in pure form.

\section{ACKLOWDEGMENT}

This work was supported by a grant to the Korea Polar Research Institute, KOPRI, under a project 12040. Field visit was supported by Korea Research Foundation Grant (MOEHRD, Basic Research Promotion Fund) (KRF-2008313-C00801).

\section{REFERENCES}

ING'OLFD'OTTIR K (2002) Molecules of interest usnic acid. Phytochem 61:729-736.

KUMAR KCS, MÜLLER K (1999) Lichen metabolites. 1. Inhibitory action against leukotriene $\mathrm{B}_{4}$ biosynthesis by a non-redox mechanism. J Nat Prod 62:817-820.

VARTIA KO (1973) Antibiotics in lichens: In V. Ahmadjian and M. E. Hale (ed.), The lichens. Academic Press, New York pp. 547-561.

ING'OLFD'OTTIR K, HIJALMARSDOTTIR MA, SIGURDSSON A, GUDJONSDOTTIR GA, BRYNJOLFSD'OTTIR A, STEINGRIMSSOON O (1997) In vitro susceptibility of Helicobacter pylori to protolichesterinic acid form the lichen Cetraria islandica. Antimicrob Agents Chemother 41:215-217.

DAVIES K (1995) Oxidative stress: the paradox of aerobic life. Biochemical Society Symposia 61:1-31. 
VALKO M, LEIBFRITZ D, MONCOL J, CRONIN M, MAZUR M, TELSER J (2007) Free radicals and antioxidants in normal physiological functions and human disease. International J Biochem Cell Biol, 39:44-84.

AMES BN, SHIGENAGA MK, HAGEN TM (1993) Oxidants, antioxidants and the degenerative diseases of aging. Proceedings of the National Academy of Sciences of the United States of America 901:7915-7922.

DEAN RT, DAVIES MJ (1993) Reactive species and their accumulation on radical damaged proteins. Trends Biochem Sci 18:437-441.

BHATTARAI HD, PAUDEL B, HONG SG, LEE HK, YIM JH (2008) Thin layer chromatography analysis of antioxidant constituents of lichens from Antarctica. J Nat Med 62:481-484.

PAUDEL B, BHATTARAI HD, LEE JS, HONG SG, SHIN HW, YIM JH (2008) Antioxidant activity of polar lichens from King George island (Antarctica). Polar Biol 31:605-608.

BBP (Biodiversity Profile Project) (1995) Enumeration of the Lichens of Nepal, HMG Nepal and Government of Netherlands, Kathmandu, Nepal,1-70.

BHATTARAI HD, LEE YK, CHO KH, LEE HK, SHIN HW (2006) The study of antagonistic interactions among pelagic bacteria: a promising way to coin environmentally friendly antifouling compounds. Hydrobiol 568:417-423.

SWENSON JM, THORNSBERRY C, SILCOX VA (1982) Rapidly growing mycobacteria: testing of susceptibility to 34 antimicrobial agents by micro dilution. Antimicrob Agents Chemother 22:186-192.
BLOIS MS (1958) Antioxidant determinations by the use of a stable free radical. Nature 26:1199-1200.

RICE-EVANS C, MILLER NJ (1994) Total antioxidant status in plasma and body fluids. Meth Enzymology 234:279-293.

OYAIZU M (1986) Studies on product of browning reaction prepared from glucose amine. Jpn J Nutr 44:307-315.

BHATTARAI HD, PAUDEL B, LEE HS, LEE YK, YIM JH (2008) Antioxidant activity of Sanionia uncinata, a polar moss species from King George Island, Antarctica. Phytother Res 22:1635-1639.

MEYER BN, FERRIGN RN, PUTNAM JE, JACOBSON LB, NICHOLAS DE, Mclaughlin JL (1982) Brine shrimp: A convenient general bioassay for active plant constituents. Planta Med 45:31-34.

HUANG D, OU B, PRIOR RL (2005) The chemistry behind antioxidant capacity assays. J Agric Food Chem 53:1841-1856.

DUH PD, TU YY, YEN GC (1999) Antioxidant activity of aqueous extract of harn jyur (Chrysanthemum morifolium Ramat). LWT 32: 269-277.

MEIR S, KANNER J, AKIRI B, HADAS SP (1995) Determination and involvement of aqueous reducing compounds in oxidative defense systems of various senescing leaves. J Agric Food Chem 43:1813-1817.

GORDON MH (1990) The mechanism of antioxidant action in vitro. In Hudson BJF (Ed.). Food antioxidants. London: Elsevier Applied Science. $1-18$.

RANKOVIC B, RANKOVIC D, MARIC D (2010) Antioxidant and antimicrobial activity of some lichens species. Microbiol 79:809-815. 
